\title{
Balanço de energia e evapotranspiração de feijão caupi sob condições de sequeiro ${ }^{1}$
}

\author{
Energy balance and evapotranspiration in cowpea under rainfed conditions
}

\author{
José Romualdo de Sousa Lima ${ }^{2 *}$, Antonio Celso Dantas Antonino ${ }^{3}$, Carlos Alberto Brayner de Oliveira Lira ${ }^{3}$, \\ Eduardo Soares de Souza $^{4}$ e Ivandro de França da Silva ${ }^{5}$
}

\begin{abstract}
Resumo - Objetivou-se determinar os componentes do balanço de energia (saldo de radiação, fluxos de calor latente, sensível e no solo), a evapotranspiração (ET) e a eficiência no uso de água (EUA) do feijão caupi cultivado sob condições de sequeiro. O experimento foi conduzido numa área de quatro hectares, localizada no CCA/UFPB, Areia, PB (6 $6^{\circ} 58^{\prime} 12^{\prime}$ ' S e 3542'15" O e 620 m), durante o período de 22/07/2003 a 17/10/2003. Para a determinação dos componentes do balanço de energia e da ET utilizou-se o método da razão de Bowen, sendo que para isso foi instalada, no centro da área, uma torre micrometeorológica com sensores para medição da temperatura e da umidade relativa, em dois níveis acima do dossel do caupi, além de sensores para a medição do saldo de radiação, da radiação solar global, do fluxo de calor no solo e da precipitação pluvial. Verificou-se que o valor médio da razão saldo de radiação/radiação global $(\mathrm{Rn} / \mathrm{Rg})$ foi de $79 \%$, sendo a Rn utilizada, em média, como $65 \%$ no fluxo de calor latente (LE/Rn), $23 \%$ como fluxo de calor sensível (H/Rn) e $12 \%$ como fluxo de calor no solo $(\mathrm{G} / \mathrm{Rn})$. Em relação à evapotranspiração, observou-se que o valor total durante o período experimental foi $330,7 \mathrm{~mm}$ e o médio de $3,8 \mathrm{~mm} \mathrm{dia}^{-1}$. A produção do caupi foi de apenas $206,0 \mathrm{~kg} \mathrm{ha}^{-1}$, com uma EUA baixa $\left(0,06 \mathrm{~kg} \mathrm{~m}^{-3}\right)$, a qual se deu, provavelmente, devido ao déficit hídrico ocorrido na fase reprodutiva.
\end{abstract}

Palavras-chave - Relações hídricas. Eficiência no uso de água. Razão de Bowen.

\begin{abstract}
The objective of this study was to assess the energy balance components (net radiation, latent heat flux, sensible heat flux and soil heat flux), evapotranspiration (ET) and water use efficiency (WUE) of cowpea grown under rainfed conditions. The experiment was conducted in a 4 ha area in the CCA, UFPB, belonging to the Municipality of Areia, PB (6 $6^{\circ} 58^{\prime} \mathrm{S}, 35^{\circ} 41^{\prime} \mathrm{W}$ and $\left.620 \mathrm{~m}\right)$ during the period from July, 222003 to October, 17 2003. To determine the energy balance components and ET, it was used the Bowen ratio method, and for that, the area was instrumented with a micrometeorological tower containing sensors for measuring air temperature and relative humidity at two levels above the canopy of cowpea. Measurements of net and global radiation, soil heat flux and rainfall were also made. The average value of the net radiation was $79 \%$ of the global solar radiation $(\mathrm{Rn} / \mathrm{Rg})$, in which $65 \%$ appeared as latent heat flux (LE/Rn), $23 \%$ as sensible heat flux $(\mathrm{H} / \mathrm{Rn})$ and $12 \%$ as soil heat flux $(\mathrm{G} / \mathrm{Rn})$. The total and average values for actual evapotranspiration were $330.7 \mathrm{~mm}$ and $3.8 \mathrm{~mm} \mathrm{day}^{-1}$, respectively. The production of cowpea was only $206.0 \mathrm{~kg} \mathrm{ha}^{-1}$ with low WUE $\left(0.06 \mathrm{~kg} \mathrm{~m}^{-3}\right)$, which occurred probably due to water deficit at reproductive stage.
\end{abstract}

Key words - Water relations. Water use efficiency. Bowen ratio.

\footnotetext{
*Autor para correspondência

${ }^{1}$ Recebido para publicação em 04/05/2010; aprovado em 28/01/2011

Parte da Tese do primeiro autor apresentada no Programa de Pós-Graduação em Tecnologias Energéticas e Nucleares/PROTEN/DEN/UFPE

${ }^{2}$ Unidade Acadêmica de Garanhuns/UFRPE, Av. Bom Pastor, S/N, Boa Vista, Garanhuns-PE, Brasil, 55.296-901, romualdo@uag.ufrpe.br

${ }^{3}$ Departamento de Energia Nuclear/CTG/UFPE, Recife-PE, Brasil, acda@ufpe.br, cabol@ufpe.br

${ }^{4}$ Unidade Acadêmica de Serra Talhada/UFRPE, Serra Talhada-PE, Brasil, edu_souza_pe@yahoo.com.br

${ }_{5}^{5}$ Departamento de Solos e Engenharia Rural/CCA/UFPB, Areia-PB, Brasil, ivandro@cca.ufpb.br
} 


\section{Introdução}

O feijão caupi, feijão de corda ou feijão macassar (Vigna unguiculata (L.) Walp.) tem grande importância econômica e social para a região Nordeste do Brasil, uma vez que é um dos alimentos básicos das populações de baixa renda dessa região.

O feijão caupi ocupa $60 \%$ das áreas cultivadas com feijão no Nordeste brasileiro. A maioria dos produtores de feijão caupi é composta de pequenos agricultores, em sistema de parceria e em nível de subsistência (ANDRADE JÚNIOR et al., 2007). Essa leguminosa é cultivada sob condições de sequeiro, principalmente, por pequenos produtores da região semiárida, a qual se caracteriza pela extrema variabilidade interanual da precipitação pluvial, sendo que, em alguns anos, o suprimento de água às plantas é suficiente para atingir altas produtividades, enquanto em outros anos, a falta de suprimento adequado, pode levar à perda total das colheitas.

Desse modo, é muito importante conhecer as necessidades hídricas dessa cultura, o que pode ser feito por meio da quantificação das perdas de água via evapotranspiração. Segundo Lima et al. (2005a), as pesquisas sobre evapotranspiração fornecem informações relativas a quantidade de água consumida pelas plantas, fornecendo dados para o manejo da água e para o dimensionamento dos sistemas de irrigação. A quantificação da evapotranspiração, mesmo em agricultura de sequeiro, é muito importante, pois possibilita estratégias de manejo em função das condições climáticas da região e hídricas do solo.

Os métodos utilizados para se medir a evapotranspiração variam de técnicas de medições diretas, usando os lisímetros, a medições indiretas, usando os métodos dos balanços de água e de energia, sendo esses dois últimos muito utilizados devido à sua simplicidade, robustez e menores custos (LIMA, 2004).

O balanço de energia das superfícies vegetadas permite dimensionar as trocas de massa e energia no sistema solo-planta-atmosfera, através do estudo da partição do saldo de radiação nos diversos processos que ocorrem na cultura. $\mathrm{O}$ método permite que se avaliem as alterações no microclima da vegetação, em função dos estádios de desenvolvimento da cultura e das condições de solo e atmosfera (FONTANA et al., 1991).

Várias pesquisas foram realizadas com o objetivo de se medir a ET de caupi (ANTONINO et al., 2000; BASTOS et al., 2008; LIMA et al., 2006a; LIMA et al., 2006b; SOUZA et al., 2005) e os componentes do balanço de energia (LIMA et al., 2005b; NEVES et al., 2008; SAN JOSÉ et al., 2003). No entanto, pesquisas que determinaram, simultaneamente, os componentes do balanço de energia e a evapotranspiração do caupi são escassas.
Diante disso, o presente trabalho teve como objetivo determinar a evapotranspiração, e os componentes do balanço de energia, por meio do método da razão de Bowen, em caupi cultivado sob condições de sequeiro no Brejo Paraibano.

\section{Material e métodos}

$\mathrm{O}$ experimento foi realizado em uma área de quatro hectares cultivada com feijão caupi, pertencente ao Centro de Ciências Agrárias da Universidade Federal da Paraíba (CCA/UFPB), Areia-PB (6 $6^{\circ} 58^{\prime} 12^{\prime \prime} \mathrm{S}$ e $35^{\circ} 42^{\prime} 15^{\prime \prime}$ $\mathrm{O}$ e $620 \mathrm{~m}$ ). O clima na região, pela classificação de Köppen, é do tipo As', quente e úmido, com chuvas de outono-inverno. A normal climatológica do município de Areia-PB (1961-1990) indica que o mesmo apresenta uma precipitação média anual de $1.400 \mathrm{~mm}$, temperatura média anual de $24,5{ }^{\circ} \mathrm{C}$ e umidade relativa média anual de $80 \%$. O quadrimestre mais chuvoso - constituído dos meses de abril, maio, junho e julho - representa $62 \%$ da precipitação média anual (OLIVEIRA et al., 2009).

O solo da área é classificado como Latossolo Amarelo(EMBRAPA, 2006), oqualapresentouasseguintes características químicas, determinadas utilizando-se as metodologias recomendadas pela EMBRAPA (1997): $\mathrm{pH}$ em água 5,2, P e K extraídos pelo método de Mehlich, 0,75 e $30 \mathrm{mg} \mathrm{dm}^{-3}$, respectivamente, matéria orgânica, $48 \mathrm{~g} \mathrm{dm}^{-3}$ e CTC $10,90 \mathrm{cmol}_{\mathrm{c}} \mathrm{dm}^{-3}$. A caracterização física do solo da área experimental é apresentada na Tabela 1 , sendo que a análise granulométrica foi realizada em amostras coletadas a cada $0,20 \mathrm{~m}$, até à profundidade de $0,80 \mathrm{~m}$. As frações de argila e de silte foram determinadas por sedimentação, após dispersão com hexametafosfato de sódio, utilizando-se o método do densímetro (LOVELAND; WHALLEY,1991). A densidade do solo foi determinada utilizando-se o método do anel volumétrico (EMBRAPA, 1997).

O plantio do feijão caupi foi realizado de 22 a 23/07/2003, manualmente, por meio de matracas, colocando-se duas sementes por cova, num espaçamento de $1,0 \times 0,50 \mathrm{~m}$. Durante todo o ciclo fenológico do feijão caupi foram realizadas duas capinas manuais e não se detectou a presença de pragas nem ocorrência de doenças. A colheita foi realizada no dia 17/10/2003.

Para a determinação dos componentes do balanço de energia e da evapotranspiração foi instalada uma torre micrometeorológica no centro da área cultivada com caupi. Essa torre continha dois sensores de medidas da temperatura e da umidade relativa do ar, em dois níveis $\left(\mathrm{z}_{1}=0,35\right.$ e $\mathrm{z}_{2}$ $=1,05 \mathrm{~m})$ acima do dossel da cultura. Com a evolução da altura da cultura, ocorria elevação da altura desses sensores, de modo que os níveis de medição se mantivessem nas alturas estabelecidas $\left(\mathrm{z}_{1}=0,35\right.$ e $\left.\mathrm{z}_{2}=1,05 \mathrm{~m}\right)$; além desses 
Tabela 1 - Análise granulométrica, classificação textural e densidade do solo $(\rho)$ da área experimental

\begin{tabular}{|c|c|c|c|c|c|}
\hline \multirow{2}{*}{$\begin{array}{l}\text { Profundidade } \\
\text { (m) }\end{array}$} & \multicolumn{3}{|c|}{ Granulometria $\left(\mathrm{g} \mathrm{kg}^{-1}\right)$} & \multirow{2}{*}{ Classificação textural } & \multirow{2}{*}{$\begin{array}{c}\rho \\
\left(\mathrm{kg} \mathrm{dm}^{-3}\right)\end{array}$} \\
\hline & Areia & Silte & Argila & & \\
\hline $0-0,20$ & 628,9 & 140,7 & 230,4 & Franco argilo arenosa & 1,28 \\
\hline $0,20-0,40$ & 558,2 & 140,8 & 301,0 & Franco argilo arenosa & 1,33 \\
\hline $0,40-0,60$ & 470,2 & 117,3 & 412,5 & Argilo arenosa & 1,37 \\
\hline $0,60-0,80$ & 488,7 & 82,0 & 429,3 & Argilo arenosa & 1,31 \\
\hline
\end{tabular}

sensores, ainda se instalou um piranômetro para a medida da radiação global, um saldo radiômetro para a medição do saldo de radiação e um pluviógrafo, para a medida da precipitação pluvial; esses sensores foram instalados na mesma torre, na altura de $1,5 \mathrm{~m}$ da superfície do solo. Para a medida do fluxo de calor no solo instalaram-se fluxímetros em dois locais, na profundidade $\mathrm{z}=0,05 \mathrm{~m}$, juntamente com um sensor de umidade do solo, na mesma profundidade, além de duas sondas térmicas instaladas horizontalmente, nas profundidades de $\mathrm{z}_{1}=0,02$ e $\mathrm{z}_{2}=$ $0,08 \mathrm{~m}$. Todas essas medidas foram armazenadas como médias a cada 30 minutos, com exceção da pluviometria, quando foi calculado seu valor total, em um sistema de aquisição de dados CR 10X da Campbell Scientific.

O balanço de energia é descrito pela equação 1 (LIMA et al., 2005b; TODD et al., 2000):

$R n=L E+H+G$

sendo $\mathrm{Rn}$ o saldo de radiação, LE o fluxo de calor latente, $\mathrm{H}$ o fluxo de calor sensível e $\mathrm{G}$ o fluxo de calor no

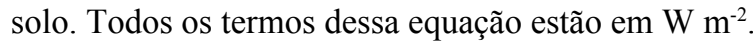

O saldo de radiação $(\mathrm{Rn})$ foi obtido por meio das medições realizadas pelo saldo radiômetro. O fluxo de calor na superfície do solo $(\mathrm{G})$ foi obtido a partir da medição do fluxo de calor pelo fluxímetro na profundidade $\mathrm{z}=0,05 \mathrm{~m}$, de acordo com Kustas et al. (2000).

Os fluxos de calor latente (LE) e calor sensível (H) foram determinados, a cada 30 minutos, pelo método do balanço de energia razão de Bowen por meio das equações 2 e 3 (LIMA et al., 2005b; TODD et al., 2000):

$$
\begin{aligned}
& L E=\frac{(R n-G)}{1+\beta} \\
& H=\frac{\beta}{1+\beta}(R n-G)
\end{aligned}
$$

sendo $\beta$ a razão de Bowen.
A razão de Bowen é obtida por meio das diferenças, a cada 30 minutos, na temperatura $\left({ }^{\circ} \mathrm{C}\right)$ do $\operatorname{ar}(\Delta \mathrm{T})$ e na pressão de vapor $(\mathrm{kPa})(\Delta \mathrm{e})$, entre os níveis $1\left(z_{1}=0,35 \mathrm{~m}\right)$ e $2\left(z_{2}=1,05 \mathrm{~m}\right)$ :

$\beta=\frac{H}{L E}=\gamma \frac{\Delta T}{\Delta e}$

sendo $\gamma$ a constante psicrométrica $\left(0,066 \mathrm{kPa}^{\circ} \mathrm{C}^{-1}\right)$.

Para evitar possíveis erros na estimativa dos fluxos de calor latente, e conseqüentemente, na evapotranspiração, os valores da razão de Bowen menores que -0,75 (ORTEGA-FARIAS et al., 1996), bem como aqueles nos quais as medições dos gradientes de temperatura e de pressão de vapor foram menores que o limite da resolução dos sensores (OHMURA, 1982), foram eliminados e substituídos por interpolação dos valores, de cada 30 minutos, precedentes e subseqüentes válidos (LIMA, 2004).

A evapotranspiração $\left(\mathrm{mm} \operatorname{dia}^{-1}\right)$ foi determinada por meio da equação 5:

$$
E t=\frac{L E}{\rho_{H_{2} O} L} 0,035
$$

sendo LE o fluxo de calor latente $\left(\mathrm{W} \mathrm{m}^{-2}\right), \rho_{\mathrm{H}_{2} \mathrm{O}}$ a massa especifica da água, considerada como constante (1000 $\left.\mathrm{kg} \mathrm{m}^{-3}\right)$ e $\mathrm{L}$ o calor latente de vaporização, considerado como constante $\left(2,45 \mathrm{MJ} \mathrm{kg}^{-1}\right)$. Esse valor constante se refere a uma temperatura de $20^{\circ} \mathrm{C}$, embora L seja uma função fraca da temperatura (LIMA et al., 2006b). O fator 0,035 foi usado para obter o valor de ET em $\mathrm{mm} \mathrm{dia}^{-1}$.

A evapotranspiração de referência (ETo) foi determinada, segundo recomendação da FAO, usandose a equação de Penman-Monteith proposta por Allen et al. (1998).

A eficiência no uso de água pelo caupi (EUA) $\left(\mathrm{kg} \mathrm{m}^{-3}\right)$ foi obtida pela seguinte equação: 


$$
E U A=\frac{P d}{E T} 0,1
$$

sendo Pd a produção de grãos do feijão caupi $\left(\mathrm{kg} \mathrm{ha}^{-1}\right)$, ET a evapotranspiração (mm). O fator 0,1 foi usado para transformar os resultados da EUA para $\mathrm{kg} \mathrm{m}^{-3}$.

Para a quantificação da produção de grãos foram selecionadas quatro áreas com $100 \mathrm{~m}^{2}$ cada uma. Após a colheita dos grãos de caupi das quatro áreas, os mesmos foram colocados para secar até atingir uma umidade de $12 \%$, sendo em seguida medidas as massas de grãos em $\mathrm{kg} \mathrm{ha}^{-1}$.

Considerou-se o seguinte período de tempo para as fases fenológicas da cultura do feijão caupi (BASTOS et al., 2001): a fase de emergência foi de 3 a 8 dias após o plantio (DAP), a fase vegetativa se estendeu dos 9 aos 51 DAP, a fase reprodutiva dos 52 aos 74 DAP, a fase de maturidade fisiológica e senescência se estendeu dos 75 aos 88 DAP.

\section{Resultados e discussão}

$\mathrm{Na}$ Figura 1 estão apresentados os dados de precipitação pluvial e as fases fenológicas do feijão caupi. Observou-se um total de chuvas de $241,40 \mathrm{~mm}$, tendo ocorrido precipitações na maior parte do tempo, à exceção dos 61 aos 80 DAP (dias após o plantio), quando não se verificou nenhuma precipitação. $\mathrm{O}$ maior evento chuvoso correspondeu a uma lâmina de $30,3 \mathrm{~mm}$, tendo ocorrido aos 26 DAP, ou seja, no dia 16/08/2003.

Verificou-se que na fase de emergência a precipitação total foi de $46,1 \mathrm{~mm}$, na fase vegetativa foi de $150,4 \mathrm{~mm}$, na fase reprodutiva a precipitação foi de apenas $10,3 \mathrm{~mm}$ e na de maturação de $34,6 \mathrm{~mm}$. Analisando-se os dados de chuva nas fases fenológicas constatou-se que na fase reprodutiva ocorreu uma escassez de precipitação, o que contribuiu para uma diminuição da produtividade do feijão caupi, uma vez que essa é uma das fases em que a cultura é mais sensível ao déficit hídrico (BEZERRA et al., 2003; CARVALHO et al., 2000; LEITE; VIRGENS FILHO, 2004).

As variações diárias da razão entre o saldo de radiação e a radiação solar global $(\mathrm{Rn} / \mathrm{Rg})$ e das razões entre os fluxos de calor latente, sensível e no solo e o saldo de radiação (LE/Rn, H/Rn e G/Rn, respectivamente) estão apresentadas na Figura 2.

Observou-se que a razão entre o saldo de radiação $(\mathrm{Rn})$ e a radiação solar global $(\mathrm{Rg})$ apresentou distribuição regular e valor médio de $0,79 \pm 0,04$, com valores máximos $(0,85$ a 0,89$)$ ocorrendo nos períodos de 2-5 DAP e de 47-50 DAP, enquanto os valores mínimos $(0,73-0,74)$ ocorrem no período de 69-78 DAP.

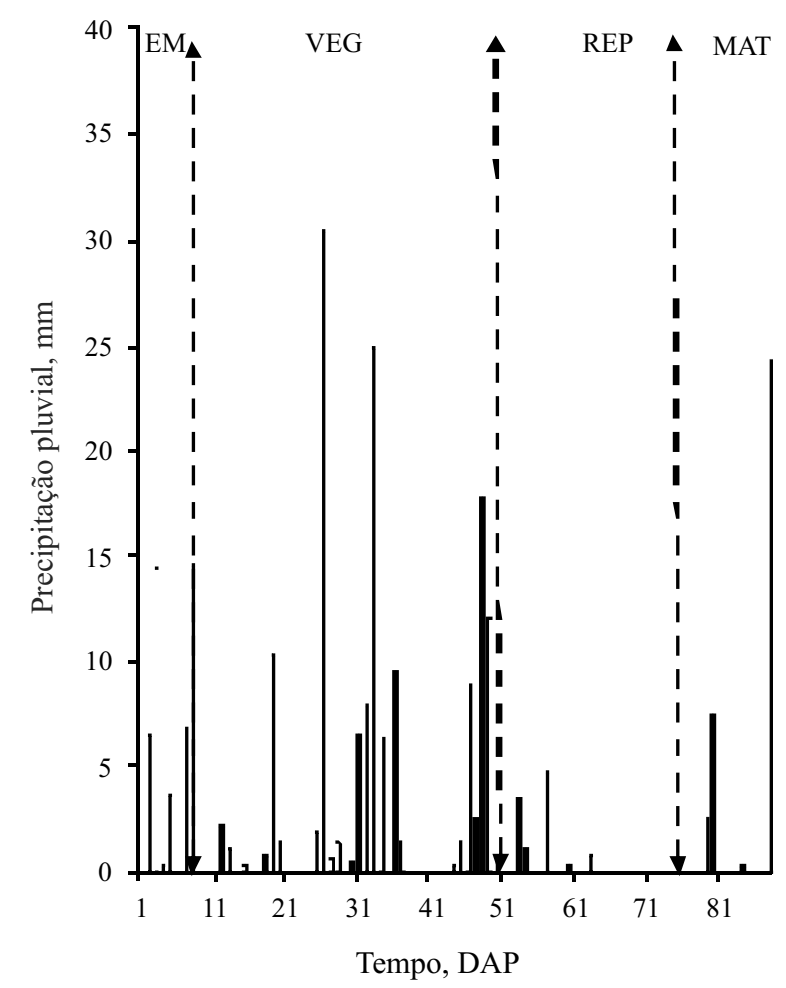

Figura 1 - Precipitação pluvial e fases fenológicas do feijão caupi durante o período de 22/07/2003 a 17/10/2003 (1 a 88 DAP, dias após o plantio) em Areia-PB. As barras verticais separam as fases fenológicas: emergência (EM), vegetativa (VEG), reprodutiva (REP) e maturação e senescência (MAT)

A razão $\mathrm{Rn} / \mathrm{Rg}$, para a parcela de radiação de ondas curtas, depende apenas do albedo, ou seja, independe do valor da radiação global incidente $(\mathrm{Rg})$; enquanto que para a parcela de radiação de ondas longas depende da radiação atmosférica (radiação de ondas longas emitida pela atmosfera em direção a superfície), da radiação terrestre e do valor de $\mathrm{Rg}$, sendo mais afetada pela radiação atmosférica.

A razão $\mathrm{Rn} / \mathrm{Rg}$ diminuirá com o aumento do albedo e da temperatura da superfície e aumentará com o aumento da radiação atmosférica. No caso de céu claro ou com pouca nebulosidade, em períodos de pouca ou nenhuma precipitação pluvial (por exemplo, dos 61 aos 80 DAP, ver FIG. 1), ocorrerá uma secagem da superfície do solo, que será mais intensa quanto mais descoberta for a superfície, o que provoca uma redução da umidade que por sua vez aumenta o albedo e a temperatura da superfície, quando comparado ao solo úmido (ALLEN et al.,1994). Nesses períodos, são observados menores valores da razão $\mathrm{Rn} / \mathrm{Rg}$. Este comportamento também foi observado nas condições semiáridas da Nigéria para um solo sem vegetação (WALLACE; HOLWILL, 1997). 


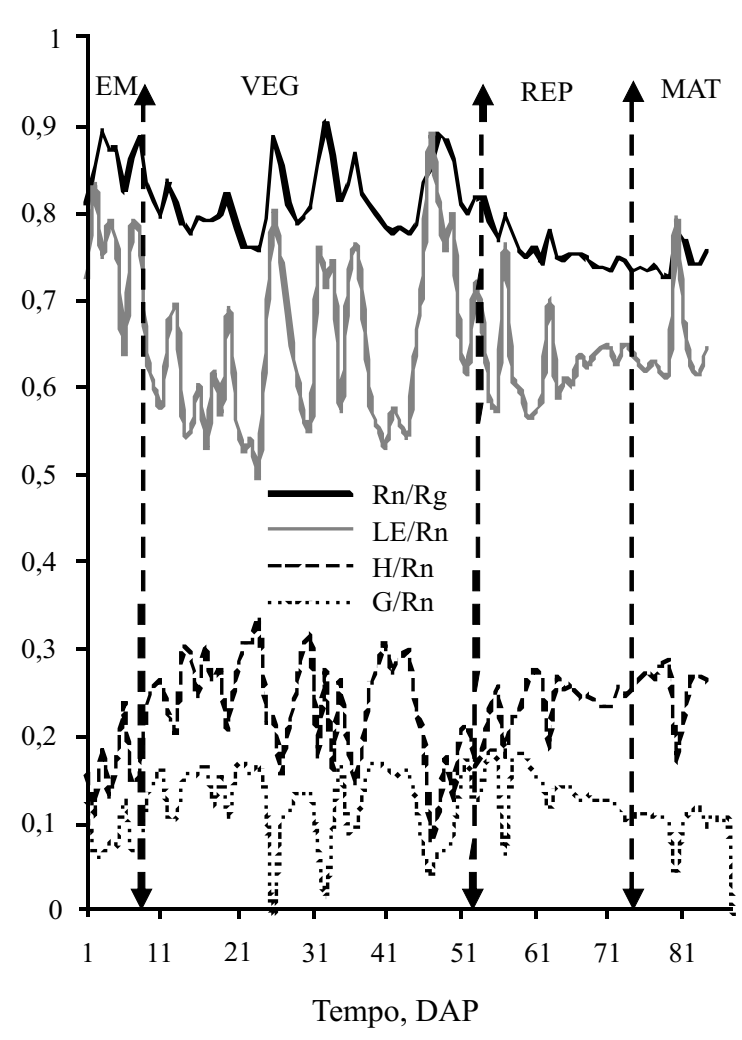

Figura 2 - Variações diárias da razão entre o saldo de radiação $(\mathrm{Rn})$ e a radiação solar global $(\mathrm{Rg})$, e das razões entre os fluxos de calor latente (LE), sensível (H) e no solo (G) e o saldo de radiação, na cultura do feijão Caupi, Areia-PB. As barras verticais separam as fases fenológicas: emergência (EM), vegetativa (VEG), reprodutiva (REP) e maturação e senescência (MAT)

Nos períodos de precipitação, com muita nebulosidade, ocorrerá uma redução da $\mathrm{Rg}$ e um aumento da irradiância atmosférica que chega à superfície, provocando maiores valores da razão $\mathrm{Rn} / \mathrm{Rg}$.

A razão LE/Rn indica a fração do saldo de radiação que será utilizada no processo de evapotranspiração. Constatou-se que maior porção do saldo de radiação $(\mathrm{Rn})$ foi utilizada como fluxo de calor latente (LE), isto é, no processo de evapotranspiração, com valor médio de 0,65 $\pm 0,09$ para todo o período estudado. Esse maior valor da razão LE/Rn, do que as outras razões (H/Rn e G/Rn), devese ao fato de que quando a camada superficial do solo está úmida, maior parte do saldo de radiação será utilizado no processo de evapotranspiração, e, como pode ser visto da Figura 1, na maior parte do período experimental ocorreram precipitações pluviais, o que fez com que essa camada ficasse mais úmida em alguns períodos.

Limaetal.(2005b), trabalhandonamesmaárea dessa pesquisa, porém num período de maior disponibilidade hídrica (março a maio de 2003), encontraram que a razão $L E / R n$ foi de 0,71 , com os valores mais elevados ocorrendo quando o solo se encontrava mais úmido. Já Neves et al. (2008), em condições de baixa disponibilidade hídrica (precipitação pluvial total igual a $2 \mathrm{~mm}$ ), mediram os componentes do balanço de energia em caupi nas condições de Tracuateua, Pará, durante os meses de agosto e setembro de 2002. Esses autores encontraram valores médios de LE/Rn igual a 0,21 , devido, principalmente, à baixa disponibilidade hídrica ao longo do ciclo da cultura.

O valor médio da porção do saldo de radiação utilizada como fluxo de calor sensível $(\mathrm{H} / \mathrm{Rn})$ foi de $0,23 \pm 0,06$, com os maiores valores $(0,30$ a 0,34$)$ ocorrendo justamente nos períodos em que a razão $\mathrm{LE} / \mathrm{Rn}$ foi menor; já que nesses períodos, a disponibilidade de água na camada superficial do solo era menor. Observou-se, ainda, que dos 56 aos 80 DAP, os valores de H/Rn ficaram em torno de 0,26 , o que ocorreu, provavelmente, devido a uma maior cobertura do solo pela cultura.

Já a porção do saldo de radiação utilizada para o fluxo de calor no solo $(\mathrm{Rn} / \mathrm{G})$, apresentou valor médio de $0,12 \pm 0,05$, sendo os maiores valores $(0,15-0,19)$ encontrados no início do cultivo, pois o solo se encontrava desnudo, e nos períodos em que o solo se encontrava com um menor conteúdo de água, ou seja, nos períodos de menores precipitações.

A variação horária dos componentes do balanço de energia para dois dias de cada fase fenológica do feijão caupi é apresentada nas Figuras 3 a 6 . Esses dias foram escolhidos baseados na precipitação pluvial ocorrida nos mesmos, com o intuito de demonstrar como ocorre a partição do saldo de radiação, nos fluxos de calor latente, sensível e no solo, para dias mais secos e mais chuvosos.

Os dados da fase de emergência, nos dias 25/07/2003 e 27/07/2003 são apresentados, respectivamente, nas Figuras 3A e 3B. Observou-se no dia 25/07/2003, aos 4 DAP, (FIG. 3A) que o fluxo de calor latente (LE) foi o principal componente do saldo de radiação $(\mathrm{Rn})$, enquanto a parcela do saldo de radiação usada como fluxo de calor sensível (H) foi bem menor. Já no dia 27/07/2003 (6 DAP), observou-se que houve um aumento na porção de Rn usada como $\mathrm{H}$, no entanto, o LE continuou a ser o principal componente do Rn (FIG. 3B.). Este comportamento dos fluxos de calor latente e sensível para o dia 25/07/2003 pode ser explicado pela precipitação de $14,4 \mathrm{~mm}$ ocorrida no dia anterior, ou seja, aos 3 DAP (FIG. 1), fazendo com que houvesse uma maior quantidade de água no solo, o que causou uma elevação do fluxo de calor latente, com uma consequente diminuição dos valores dos fluxos de calor sensível. No dia 27/07/2003 não ocorreu precipitação e nos dias anteriores só havia chovido em torno de 4,0 mm (FIG. 1). 

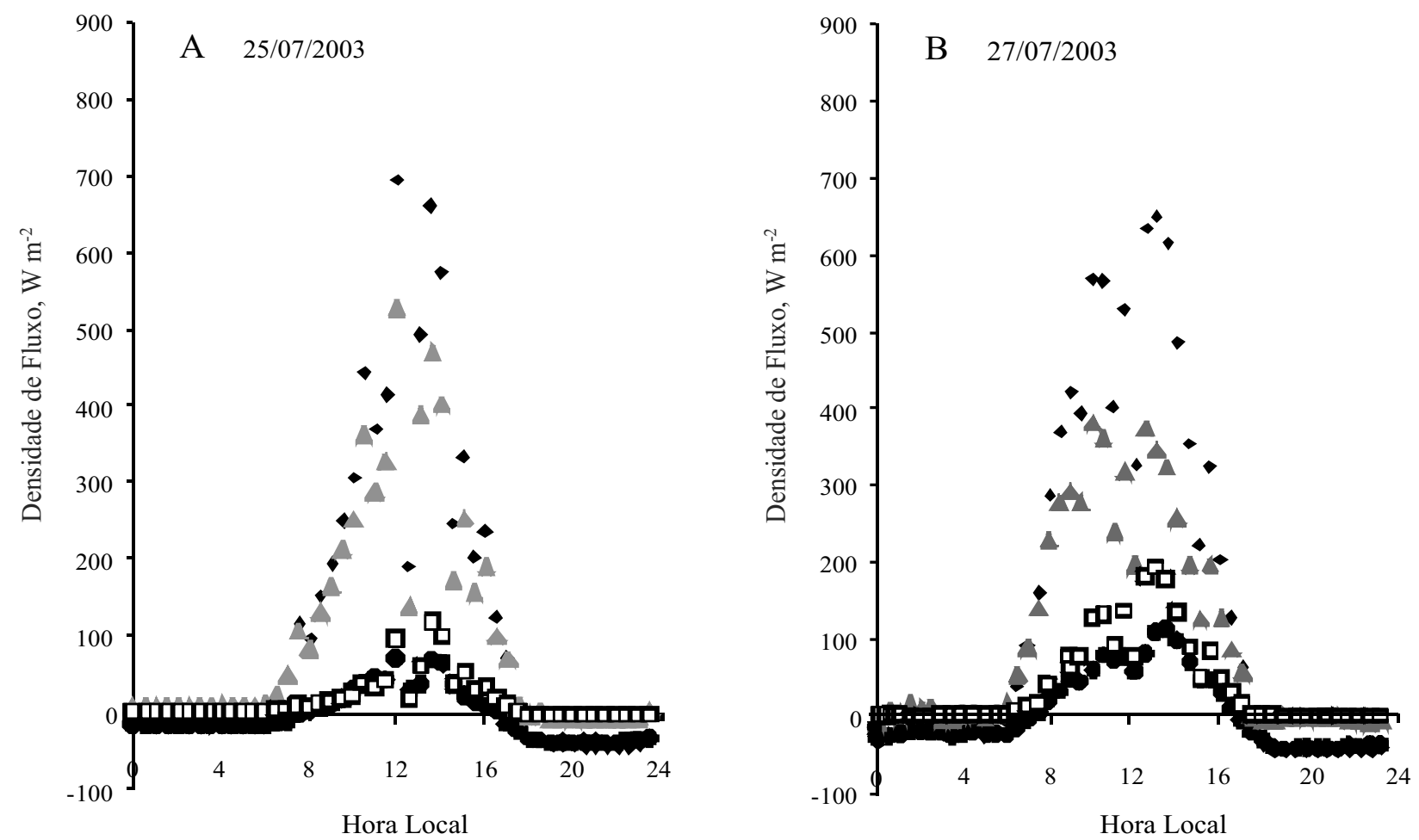

$\bullet \mathrm{Rn} \quad \mathrm{G} \quad \mathrm{ALE} \quad \mathbf{\square} \mathrm{H}$

Figura 3 - Variação horária dos componentes do balanço de energia em caupi durante a fase de emergência nos dias 25/07/2003 (A) e $27 / 07 / 2003$ (B)

As respostas observadas nos dias 25/07/2003 e 27/07/2003 mostraram os processos que ocorreram na superfície do solo descoberto, já que, quanto maior o conteúdo de água no solo, maior também a quantidade de energia utilizada no processo de evaporação da água do solo; contudo, quando se iniciou a secagem do solo, a maior parte do saldo de radiação começou a ser usada no processo de aquecimento do ar e do solo, já que nesta fase de emergência, a cultura não exerceu nenhum papel nos processos de troca de energia, na interface solo-planta-atmosfera, como, também, foi observado por Lima et al. (2002) e Lima et al. (2005b).

A variação horária dos componentes do balanço de energia, quando a cultura se encontrava na fase vegetativa é apresentada na Figura 4. Observou-se no dia 27/08/2003, aos 37 DAP, que o fluxo de calor latente (LE) foi bem maior que os fluxos de calor sensível (H) e no solo (G) (FIG. 4A), sendo que a fração evaporativa (LE/(Rn-G)) foi cerca de $84 \%$. Já para o dia 31/08/2003 (FIG. 4B), aos 41 DAP, verificou-se que houve um aumento nos valores de $\mathrm{G}$ e $\mathrm{H}$, fazendo com que houvesse uma redução da fração evaporativa para $63 \%$.
A diferença encontrada entre os dias 27/08/2003 (37 DAP) e 31/08/2003 (41 DAP), deve-se à quantidade de precipitação ocorrida, uma vez que no período de 21 a 27/08/2003 (31 a 37 DAP) tinha chovido 56,6 mm, e dos dias 28 a 31/08/2003 (38 a 41 DAP), não ocorreram precipitações (FIG. 1).

O valor médio da fração evaporativa para a fase vegetativa foi de $72,8 \%$, sendo que San José et al. (2003) encontraram valores médios dessa fração igual a $71 \%$, durante a fase vegetativa de dois cultivares de feijão caupi, cultivados nas condições tropicais da Venezuela.

A variação horária dos componentes do balanço de energia, quando a cultura se encontrava na fase reprodutiva é apresentada na Figura 5.

Observou-se para o dia 17/09/2003, aos 58 DAP, que o fluxo de calor latente foi o principal componente do saldo de radiação (FIG. 5A), o mesmo ocorrendo para o dia 28/09/2003 (69 DAP), como indicado na Figura 5B, independentemente da quantidade de água precipitada, uma vez que no dia 16/09/2003 choveu em torno de 5,0 $\mathrm{mm}$ e no dia 28/09/2003 não ocorreram precipitações (FIG. 1). 

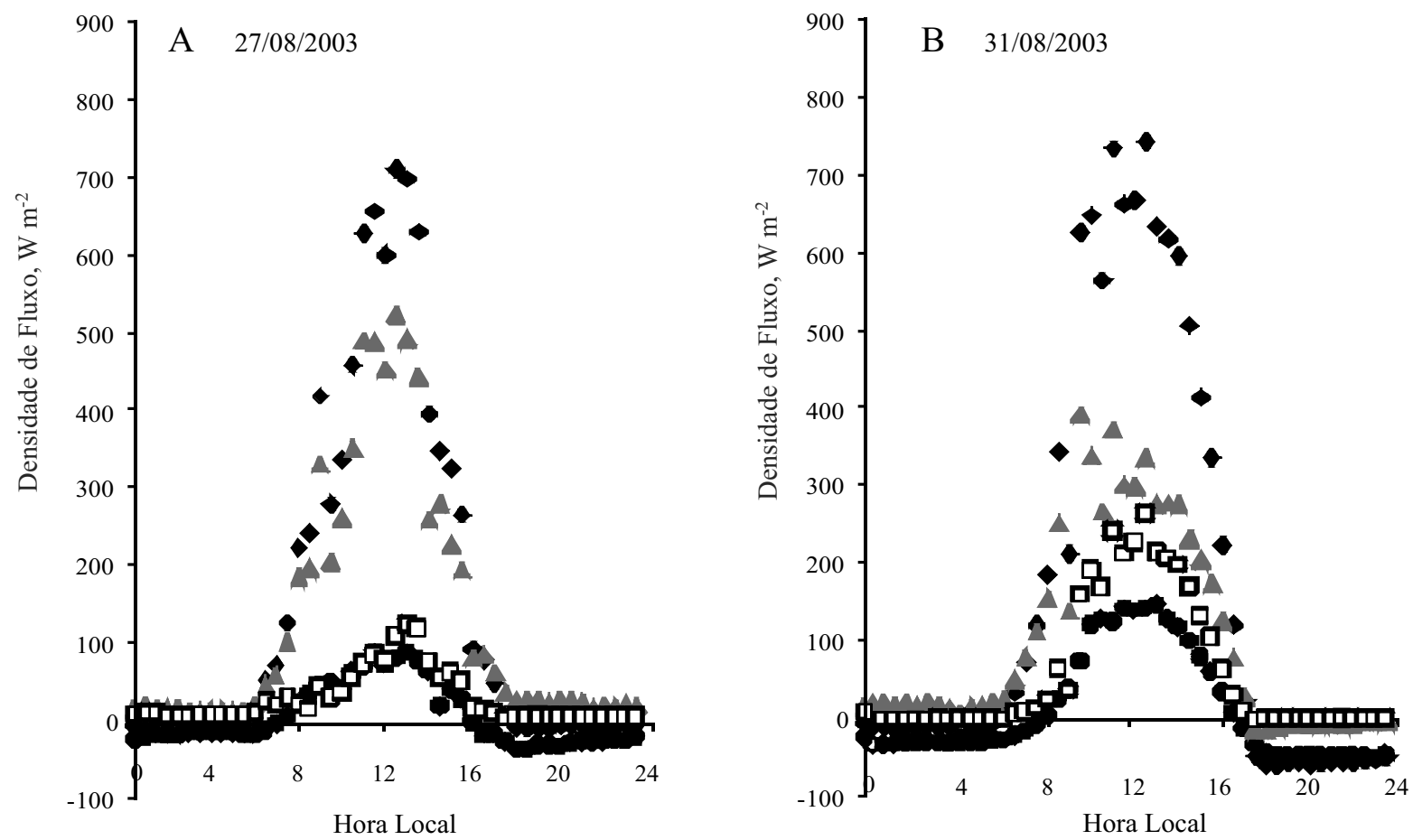

- Rn $\triangle \mathrm{GE}$ 口H

Figura 4 - Variação horária dos componentes do balanço de energia em caupi durante a fase vegetativa nos dias 27/08/2003 (A) e $31 / 08 / 2003$ (B)
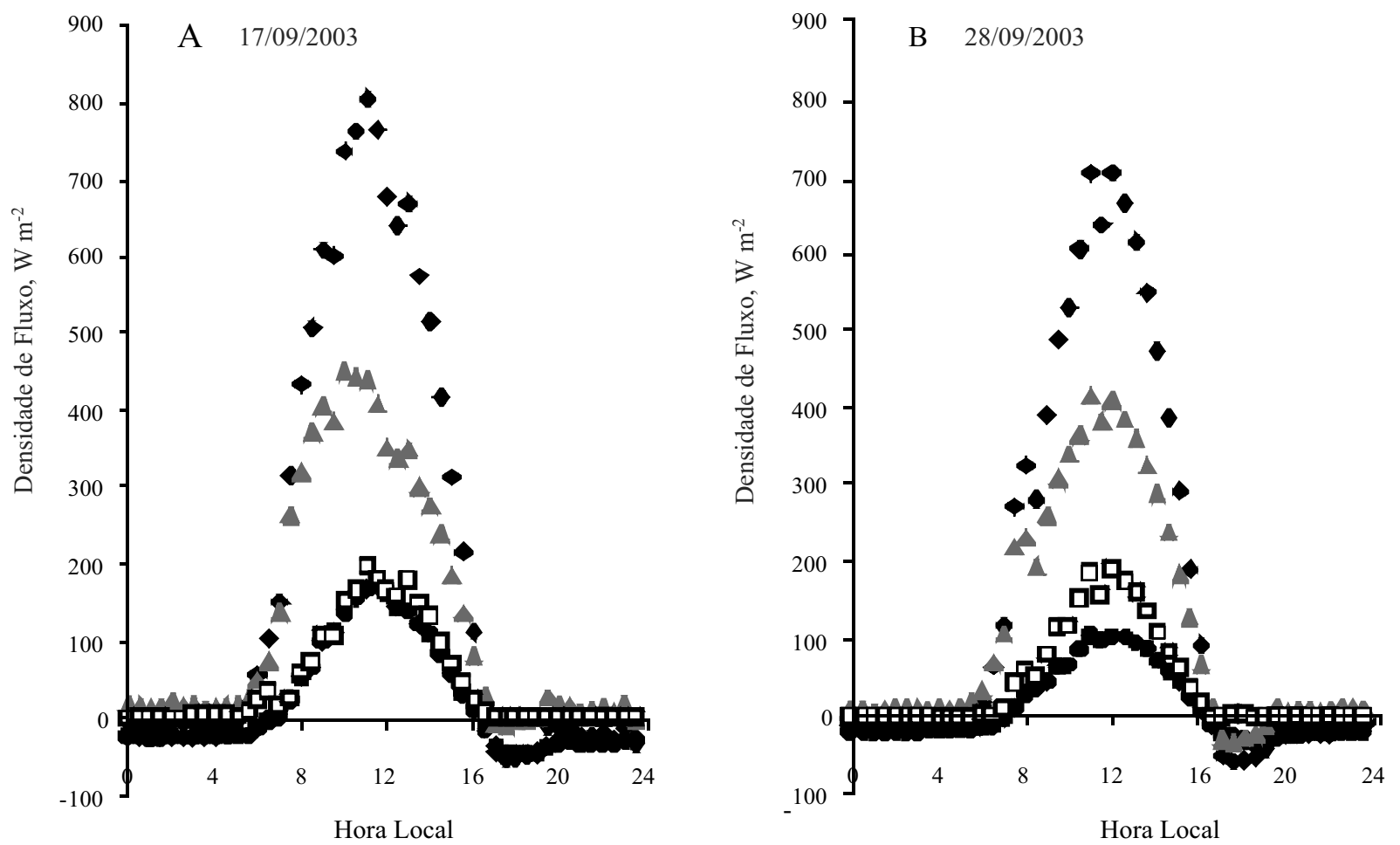

$\diamond \mathrm{Rn} \bigcirc \mathrm{G} \quad \mathrm{LE} \mathrm{D}$

Figura 5 - Variação horária dos componentes do balanço de energia em caupi durante a fase reprodutiva para os dias 17/09/2003 (A) e $28 / 09 / 2003$ (B) 
É de supor que, no dia 28/09/2003, o feijão caupi estivesse extraindo água armazenada no solo de camadas mais profundas, contribuindo, dessa forma para a manutenção dos elevados valores do fluxo de calor latente.

O valor médio da fração evaporativa para a fase reprodutiva foi $73 \%$, ou seja, igual ao valor da fase vegetativa; no entanto, esperavam-se valores mais elevados, uma vez que durante a fase reprodutiva, a cultura utiliza uma quantidade de água bem maior nos seus processos fisiológicos, do que nas fases anteriores, desse modo, ocorre um aumento da evapotranspiração, ou seja, do fluxo de calor latente (LE). Provavelmente, se não tivesse ocorrido escassez de chuva na fase reprodutiva, a fração evaporativa seria bem mais elevada nesta fase fenológica.

San José et al. (2003) na Venezuela, encontraram para dois cultivares de feijão caupi, durante a fase reprodutiva valores médios de fração evaporativa de 0,79 .

A evapotranspiração real do feijão caupi (ET) e a evapotranspiração de referência (ETo) são apresentadas na Figura 6.

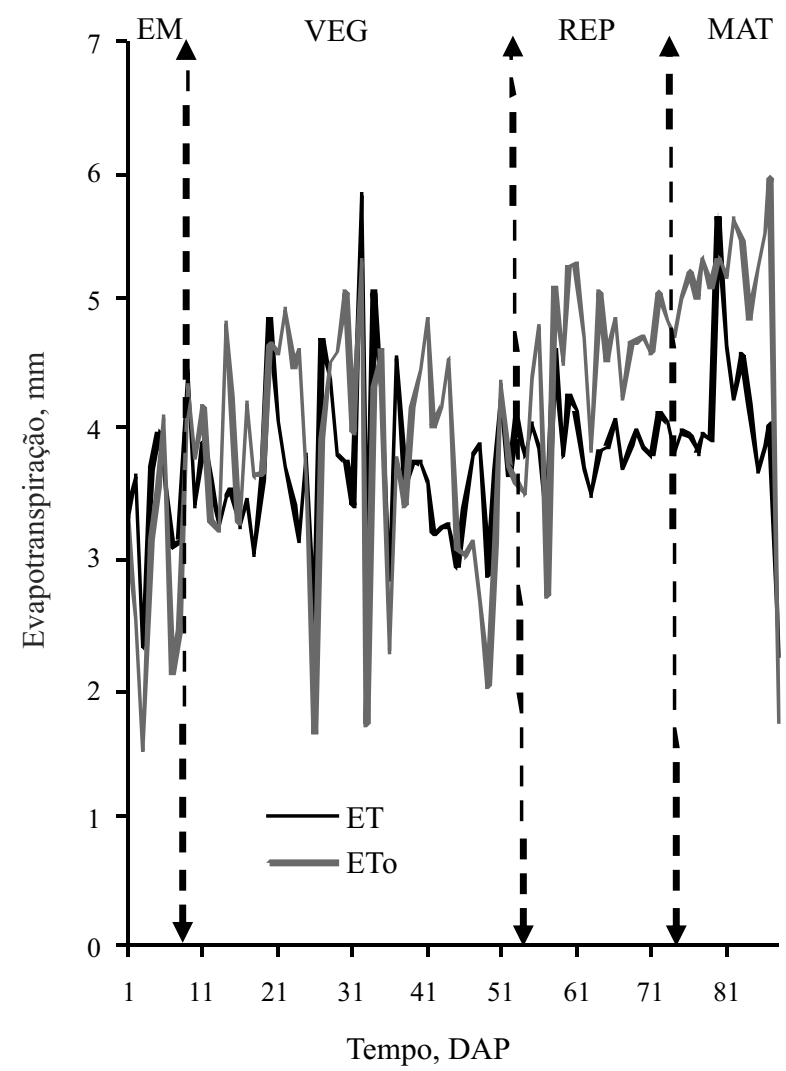

Figura 6 - Evapotranspiração do feijão caupi (ET) e evapotranspiração de referência (ETo) durante o período de 22/07/2003 a 17/10/2003 (1 a 88 DAP) em Areia-PB. As barras verticais separam as fases fenológicas: emergência $(E M)$, vegetativa (VEG), reprodutiva (REP) e maturação e senescência (MAT)
Verificou-se que os valores da evapotranspiração diária do caupi (ET) apresentaram flutuações, variando entre 2,24 e 5,81 $\mathrm{mm} \mathrm{dia}^{-1}$. Na fase de emergência, a evapotranspiração média do caupi foi de $3,3 \mathrm{~mm}$ dia $^{-}$ ${ }^{1}$. Na fase vegetativa ocorreram precipitações mais elevadas $(150,4 \mathrm{~mm})$, como indicado na Figura 1, portanto, um período com maior conteúdo de água no solo, o que favoreceu a ocorrência de valores de evapotranspiração mais elevados, com valor médio de $3,7 \mathrm{~mm} \mathrm{dia}{ }^{-1}$. Durante a fase reprodutiva ocorreram apenas 10,3 mm de chuva (FIG. 1), no entanto, a evapotranspiração média foi um pouco maior que na fase vegetativa $\left(3,9 \mathrm{~mm} \mathrm{dia}^{-1}\right)$, provavelmente, por se tratar da fase em que o caupi utiliza mais água em seus processos fisiológicos, sendo que a água necessária para esses processos, provavelmente, estava armazenada no solo. Já na fase de maturação o valor médio de ET foi praticamente igual ao da fase reprodutiva $\left(4,0 \mathrm{~mm} \mathrm{dia}^{-1}\right)$. Esse valor um pouco mais elevado de ET nesta fase pode ser devido aos valores de precipitação ocorridos nos dias 08 e 09/10/2003 (79 e 80 DAP) e no dia 17/10/2003 (88 DAP), que totalizaram $34 \mathrm{~mm}$ (FIG. 1). Ressalta-se que, provavelmente, esses valores elevados de ET devam ser originados da evaporação do solo, já que nessa fase a cultura começa a perder suas folhas.

A evapotranspiração média diária da cultura do caupi para todo o ciclo fenológico foi de $3,8 \mathrm{~mm} \mathrm{dia}^{-1}$, com um total de $330,7 \mathrm{~mm}$. Já a ETo teve valor médio de $4,12 \mathrm{~mm} \mathrm{dia}^{-1}$ e total de $362,1 \mathrm{~mm}$.

Apesar do valor de ET médio mais elevado na fase reprodutiva, observa-se que o feijão caupi deve ter passado por um estresse hídrico nessa fase, uma vez que os valores de ETo estão bem acima dos valores de ET. Essa afirmação de que a cultura do caupi deve ter passado por estresse hídrico, está baseada no fato de que na fase reprodutiva os valores de ET são, geralmente, maiores que na fase vegetativa, o que pode ser inferido de valores de coeficiente de cultura $(\mathrm{kc}=\mathrm{ETm} / \mathrm{ETo}, \mathrm{ETm}$ evapotranspiração máxima) acima da unidade.

Neste trabalho, os valores médios de ET/ETo para as fases vegetativa, reprodutiva e de maturação foram: 0,$99 ; 0,88$ e 0,83 , respectivamente. Souza et al. (2005) estimaram o kc de feijão caupi, cultivado sob irrigação em Fortaleza-CE, para as fases vegetativa, reprodutiva e de maturação. Os valores médios de kc para essas fases foram: 0,$78 ; 1,27$ e 0,69 , respectivamente. Para as condições do vale do Gurguéia-Piauí, Bastos et al. (2008) determinaram a evapotranspiração e o kc de caupi irrigado, cultivado em lisímetros de pesagem. Os coeficientes de cultivo $(\mathrm{kc})$ para a fase vegetativa variaram de 0,8 a 1,1 e na fase reprodutiva variaram de 1,1 a 1,4. Já para as condições semiáridas de Coxixola-PB, Antonino et al. (2000), cultivaram feijão 
caupi em condições de sequeiro, e encontraram valores de ET/ETo para a fase reprodutiva do caupi variando de 0,2 a 0,6 , e justificaram esse valor devido aos baixos valores de precipitação pluvial e de armazenamento de água no solo. Pelos resultados dessas pesquisas, vê-se que quando o caupi não sofreu estresse hídrico (condições irrigadas) o valor de kc na fase reprodutiva foi sempre maior que 1, indicando que a ET foi maior que a ETo. O contrário se deu quando o caupi passou por estresse hídrico.

A produção de grãos secos do feijão caupi foi de apenas 206,0 $\mathrm{kg} \mathrm{ha}^{-1}$, considerada baixa, uma vez que a média nacional é de $303,5 \mathrm{~kg} \mathrm{ha}^{-1}$ (Levantamento Sistemático da Produção Agrícola, 1993-2001). Um dos fatores que deve ter contribuído para essa baixa produtividade foi a pequena quantidade de chuvas ocorridas nas fases reprodutiva e de maturação (FIG. 1). Lima (2004), trabalhando com a mesma cultura e na mesma área experimental, encontraram valores de 813 e $888,5 \mathrm{~kg} \mathrm{ha}^{-1}$, no entanto, a distribuição da precipitação pluvial foi regular durante todo ciclo do caupi.

A eficiência no uso de água (EUA) foi de apenas $0,06 \mathrm{~kg} \mathrm{~m}^{-3}$. Esse valor tão pequeno de EUA foi devido, principalmente, à baixa produtividade do feijão caupi. Esses valores de EUA estão bem abaixo daqueles recomendados por Doorenbos e Kassam (1994) para feijão phaseolus, cujos valores variam de $0,30-0,60 \mathrm{~kg} \mathrm{~m}^{-3}$. Bernardo et al. (1996), trabalhando com feijão caupi na zona da mata pernambucana, encontraram valores de EUA de 0,32 e $0,43 \mathrm{~kg} \mathrm{~m}^{-3}$, para períodos secos e chuvosos, respectivamente.

Sob condições irrigadas, Andrade Júnior et al. (2002) encontraram EUA variando de 41,3 a 71,8 $\mathrm{kg} \mathrm{m}^{-3}$, para duas variedades de feijão caupi nas condições de Parnaíba-PI. Já sob condições de sequeiro em CoxixolaPB, Antonino et al. (2000) EUA de 0,07 kg m valores muito próximos ao desta pesquisa.

\section{Conclusões}

1. A radiação solar global transformada em saldo de radiação teve valor médio de $79 \%$, apresentando distribuição regular. Já o saldo de radiação foi utilizado, em média, como $65 \%$ no fluxo de calor latente, $23 \%$ como fluxo de calor sensível e $12 \%$ como fluxo de calor no solo;

2. A evapotranspiração total e média do feijão caupi foi $330,7 \mathrm{~mm} \mathrm{e} 3,8 \mathrm{~mm} \mathrm{~d}^{-1}$, respectivamente;

3. O feijão caupi passou por déficit hídrico na fase reprodutiva o que concorreu para as baixas produtividade e eficiência no uso de água;

\section{Referências}

ALLEN, R. G. et al. Crop evapotranspiration: guidelines for predicting crop water requirements. Rome: FAO, 1998. 300 p.

ALLEN, S. J. et al. Measurements of albedo variation over natural vegetation in the Sahel. International Journal of Climatology, v. 14, n. 06, p. 625-636, 1994.

ANDRADE JÚNIOR, A. S. et al. Níveis de irrigação na cultura do feijão caupi. Revista Brasileira de Engenharia Agrícola e Ambiental, v. 06, n. 01, p. 17-20, 2002.

ANDRADE JÚNIOR, A. S. et al. Zoneamento de risco climático para a cultura do feijão-caupi no Estado do Ceará. Revista Ciência Agronômica, v. 38, n. 01, p. 109-117, 2007.

ANTONINO, A. C. D. et al. Balanço hídrico em solo com cultivos de subsistência no semiárido do nordeste do Brasil. Revista Brasileira de Engenharia Agrícola e Ambiental, v. 04, n. 01, p. 29-34, 2000.

BASTOS, E. A. et al. Evapotranspiração e coeficiente de cultivo do feijão-caupi no vale do Gurguéia, Piauí. Irriga, v. 13, n. 02, p. 182-190, 2008.

BASTOS, E. A. et al. Simulation of growth and development of irrigated cowpea in Piauí State by CROPGRO model. Pesquisa Agropecuária Brasileira, v. 37, n. 10, p. 1381-1387, 2001.

BERNARDO, A. L. et al. Evapotranspiração da cultura do feijão caupi na Zona da Mata de Pernambuco. In: CONGRESSO GERAL DE ENERGIA NUCLEAR, 4., 1996, Rio de Janeiro. Anais... Rio de Janeiro: Associação Brasileira de Energia Nuclear, 1996. 1 CD.

BEZERRA, F. M. L. et al. Feijão caupi e déficit hídrico em suas fases fenológicas. Revista Ciência Agronômica, v. 34, n. 01 , p. 5-10, 2003.

CARVALHO, J. A. et al. Efeito do déficit hídrico sobre o rendimento do feijão cuapi (Vigna inguiculata (L) Walp). Ciência e Agrotecnologia, v. 24, n. 03, p. 710-717, 2000.

DOORENBOS, J.; KASSAM, A. H. Efeito da água no rendimento das culturas. Campina Grande: UFPB, 1994. 306 p.

EMBRAPA. Centro Nacional de Pesquisa de solos. Manual de métodos de análises de solo. 2. ed. Rio de Janeiro: Embrapa Solos, 1997. $212 \mathrm{p}$.

EMBRAPA. Centro Nacional de Pesquisa de solos. Sistema brasileiro de classificação de solos. Rio de Janeiro: Embrapa Solos, 2006. 306 p.

FONTANA, D. C.; BERLATO, M. A.; BERGAMASCHI, H. Balanço de energia em soja irrigada e não irrigada. Pesquisa Agropecuária Brasileira, v. 26, n. 03, p. 403-410, 1991.

KUSTAS, W. P. et al. Variability in soil heat flux from a mesquite dune site. Agricultural and Forest Meteorology, v. 103, n. 03, p.249-264, 2000

LEITE, M. L.; VIRGENS FILHO, J. S. Produção de matéria seca em plantas de caupi (Vigna inguiculata (L) Walp) submetidas a déficits hídricos. Publicatio UEPG: Ciências Exatas e da Terra, Agrárias e Engenharias, v. 10, n. 01, p. 43-51, 2004. 
LIMA, J. R. S. Balanço hídrico e de energia em solo cultivado e sem vegetação, para as condições do Brejo Paraibano. 2004. 167 f. Tese (Doutorado em Tecnologias Energéticas e Nucleares) - Universidade Federal de Pernambuco, Recife.

LIMA, J. R. S. et al. Balanço de energia em um solo cultivado com feijão caupi no brejo paraibano. Revista Brasileira de Engenharia Agrícola e Ambiental, v. 09, n. 04, p. 527-534, 2005 b.

LIMA, J. R. S. et al. Balanço hídrico no solo cultivado com feijão caupi. Revista Brasileira de Ciências Agrárias, v. 01, n. único, p. 89-95, 2006 a.

LIMA, J. R. S. et al. Estimativa da evapotranspiração do feijão caupi utilizando o modelo de Penam-Monteith. Irriga, v. 11, n. 04 , p. $477-491,2006$ b.

LIMA, J. R. S. et al. Estimativa da evapotranspiração em uma cultura de feijão caupi, nas condições do Brejo Paraibano. Revista Agropecuária Técnica, v. 26, n. 02, p. 86-92, 2005a.

LIMA, J. R. S. et al. Evaporação da água de um solo sem vegetação no Brejo Paraibano. Revista Brasileira de Pesquisa e Desenvolvimento, v. 04, n. 03, p. 1550-1555, 2002.

LOVELAND, P. J.; WHARLEY, R. W. Particle size analysis. In: Smith K. A.; Mullins C. E. Soil Analysis: physical methods. New York: Marcel Dekker, 1991. cap. 6, p. 271-328.

NEVES, L. O. et al. Balanço de energia em uma cultura de feijão caupi (Vigna unguiculata L.) no estado do Pará. Revista Brasileira de Agrometeorologia, v. 16, n. 01, p. 21-30, 2008.
OHMURA, A. Objective criteria for rejecting data for Bowen ratio flux calculations. Journal of Applied Meteorology, v. 21, n. 04, p. 595-598, 1982.

OLIVEIRA, I. A. et al. Balanço de energia em mamona cultivada em condições de sequeiro no Brejo Paraibano. Revista Brasileira de Ciências Agrárias, v. 4, n. 02, p. 185-191, 2009.

ORTEGA-FARIAS, S. O. et al. Daytime variation of sensible heat flux estimated by the bulk aerodynamic method over a grass canopy, Agricultural and Forest Meteorology, v. 81, n. 01-02, p.131-143, 1996

SAN JOSÉ, J. J. et al. Comparative energy exchange from cowpeas (Vigna unguiculata (L) Walp cvs. TC-9-6 and M28-6-6) with differences in canopy architectures and growth durations at the Orinoco llanos. Agricultural and Forest Meteorology, v. 116, n. 03-04, p. 197-219, 2003.

SOUZA, M. S. M.; BEZERRA, F. M. L.; TEÓFILO, E. M. Coeficientes de cultura do feijão caupi na região litorânea do Ceará. Irriga, v. 10, n. 03, p. 241-248, 2005.

TODD, R. W.; EVETT, S. R.; HOWELL, T. A. The Bowen ratioenergy balance method for estimating latent heat flux of irrigated alfalfa evaluated in a semi-arid, advective environment. Agricultural and Forest Meteorology, v. 103, n. 04, p 335-348, 2000.

WALLACE, J. S.; HOLWILL, C. J. Soil evaporation from tiger-bush in southwest Niger. Journal of Hydrology, v. 188189, n. único, p. 426-442, 1997. 